\title{
Preguntas sobre preguntas
}

José Enrique Rodríguez Ibáñez

Universidad Complutense de Madrid

Permítaseme empezar diciendo que, dada la premura con la que la REIS me invita amablemente a colaborar en este debate, voy a tratar de sortear en la medida de lo posible las convenciones académicas, ordenando mis ideas y argumentaciones con la libertad y la espontaneidad del lenguaje oral.

\section{UNA PRIMERA DELIMITACIÓN CONCEPTUAL}

El término «civilización» es, cuando menos, confuso por lo proteico de su significado y acepciones en las distintas lenguas. Civilización, por ejemplo, no quiere decir exactamente lo mismo en alemán que en inglés o en español (dado que los germanos priman el componente técnico, los anglosajones el criterio de aprendizaje histórico, y el tronco de países de lenguas romances, como el nuestro, la faceta de pueblo o sociedad culturalmente autónoma). Civilización, a su vez, es un concepto ligado a otro no menos nebuloso, el de cultura, sobre el que gustosamente me extendería de no haberlo hecho ya en otro lugar recientemente. En fin, civilización puede igualmente entenderse como patrón o escala de desarrollo, material y cívico, de una colectividad.

$Y$, sin embargo, no es de extrañar que Huntington se refiriera a este correoso vocablo cuando publicó su best-seller a mediados de los noventa. Al margen de la erudición - y el fárrago — de la obra, la intencionalidad parece que esta- 
ba muy clara desde un principio: si «la paz y la guerra entre las naciones» (por emplear el afortunado título de Raymond Aron) no podía analizarse ya bajo el prisma estrictamente geoestratégico clásico - puesto que medio siglo de bipolaridad ideológica USA-URSS no pasa en balde y porque, a la vez, el fin de la guerra fría y la llegada de la sociedad global pusieron en entredicho la primacía del Estado-nación-, y si, simultáneamente, el conflicto entre grandes cosmovisiones políticas (liberalismo vs. comunismo) tampoco resulta ya de recibo en el mundo postmoderno, no quedaba otro recurso a la hora de analizar el conflicto a gran escala que volver los ojos hacia las tradiciones culturales - no exactamente nacionales o políticas-, identificadas o próximas en ocasiones con los grandes legados religiosos.

Así pues, las civilizaciones se erigirían en macrounidades del conflicto histórico, suplantando a las viejas naciones o imperios, a las clases sociales o a las ideologías. Esto, para empezar, implica una visión conflictual de la realidad que, para algunos, supone un escollo. En efecto, ¿no debería ser el conflicto o «choque» la excepción y no la norma?

Una discusión filosófica del tipo: ¡es "el estado natural del ser humano» pacífico o agresivo?, nos llevaría muy lejos. Demasiado lejos para los límites de este comentario. Pero no vale la pena eludirla. Es el ethos más o menos agresivo del ser humano lo que debe ser aceptado como punto de partida si se quieren hacer generalizaciones sobre la belicosidad reinante en el mundo. Y en esto mi punto de vista es hobbesiano y freudiano. El ser humano - y, por extensión, la civilización humana - vive una tensión permanente entre sus impulsos íntimos de signo egoísta y pugnaz y la necesidad de lograr instrumentos de gobernabilidad que aseguren la concordia relativa. Seguimos siendo los humanos, como afirmaba Lorenz, el «eslabón perdido» entre los homínidos y no un homo sapiens que la evolución no ha logrado en su plenitud.

Ahora bien, lo anterior no obsta para que me considere también un postilustrado a la manera de Habermas. El combate entre el ideal de Commonwealth o civilización y el fondo destructor de individuos y grupos constituye una secuencia sujeta a múltiples interpretaciones, entre las cuales yo escojo el triunfo azaroso de la primera a largo plazo. ¿En qué manera? Pues en la de instaurar una sociedad planetaria políticamente democrática y moralmente integrada en torno a una ética laica y universalista conciliable con el respeto a las creencias religiosas y la diversidad cultural.

Tal utopía, por supuesto, no debe confundirse con la «comunión de los santos». Ni siquiera esa hipotética sociedad planetaria democrática estaría en condiciones de superar la defensa violenta de intereses contrapuestos, la delincuencia y los abusos de poder. No obstante, la aceptación de la visión planetaria a largo plazo repelería la idea — ¿ ¿huntingtoniana? - del enfrentamiento permanente e inevitable entre grandes colectivos humanos separados por barreras preferentemente étnicas o religiosas.

Para entendernos: no niego que las sucesivas etapas conocidas de la historia humana han vivido presididas por un conflicto central — tirios y troyanos, 
romanos y cartagineses, egipcios y persas, chinos y mongoles, españoles e ingleses, católicos y protestantes, cristianos y «turcos», etc.- - Sin embargo, no deseo hacer de todo ello una filosofía trágica de la historia. Si Europa, mal que bien, va superando dificultosamente sus viejas querellas intestinas que tanta sangre y odio han generado siglo tras siglo, ¿por qué no extender mutatis mutandis el esquema al resto del mundo?

El lector escéptico ante mis argumentos puede muy legítimamente responder: pues, sencillamente, porque ningún esquema que siempre es regional puede imponerse al mundo entero y porque, además, la gravedad y envergadura de lo sucedido el 11 de septiembre de 2001 invalidan las esperanzas postilustradas.

Bien, aterricemos en el presente. ¿Corrobora el brutal parto neoyorquino del siglo XXI la tesis del "choque» permanente de macrounidades históricas que podemos denominar convencionalmente "civilizaciones»? En mi opinión, no. Dicho parto corrobora, claro está, el precavido punto de arranque hobbesiano y freudiano al que antes me refería, pero no una visión catastrofista ad aeternum. Trataré de aportar algunas claves que justifiquen esta conclusión.

\section{UN PRESENTE DESCONCERTANTE}

Resumamos lo tantas veces visto por televisión y nunca acabado de creer del todo. Aquel día del verano declinante, cuatro grupos de activistas de una organización violenta y de nombre hasta entonces poco divulgado - $\mathrm{Al}$ Qaeda- lograban lo que ni el más imaginativo creador de historias de política-ficción hubiera concebido jamás: el secuestro de cuatro aviones de pasajeros y su conducción hacia objetivos de enorme resonancia como representación material del poder de los Estados Unidos, estrellándolos contra ellos en un ejercicio de autoinmolación, con el resultado — sobre todo en lo relativo a las Torres Gemelas de Nueva York- de muerte y destrucción masivas. Disciplina, disposición hacia un suicidio planeado con meses o años de antelación, discreción, capacidad organizativa, medios materiales, financiación; todo logrado con éxito, con la salvedad del cuarto avión, cuyo estrellamiento nadie sabe si fue fruto de forcejeos a bordo o de un derribo por parte de la aviación militar. Las consecuencias: una guerra en Afganistán contra un enemigo vidrioso identificado con el rostro de un misterioso millonario saudí y la sensación popular de que el mundo musulmán vira hacia un radicalismo imparable que evoca las epopeyas de Saladino.

Hasta aquí, la primera impresión o imagen hacia lo que todo el mundo, incapaz de sustraerse a la emoción, tiende a buscar refugio. Pero la situación no permite que los acontecimientos se reduzcan a una historia o tebeo de buenos y malos, con guerreros invencibles y animados por la fe que mueve montañas a un lado, y profesionales fríos de la guerra tecnológica a otro. Es preciso ser analítico, desglosar factores o variables y mantener la cabeza serena, por 
muy increíble que nos resulte todo y por mucho que, aparentemente, nos quedemos inermes a la hora de enjuiciar y sacar nuestras conclusiones.

Vayamos, pues, por partes:

En primer lugar, no concibamos al Islam como un todo monolítico y sin fisuras dispuesto a mostrar su faz más agresiva. Los países islámicos constituyen un enorme mosaico de etnias, regímenes políticos y hasta concepciones de la religión fundada por Mahoma. No siguen los mismos pasos. Han llegado a protagonizar guerras entre sí. Algunos, como Arabia, concilian la ortodoxia religiosa con un extremo conservadurismo político. Otros hacen de aquella ortodoxia bandera revolucionaria, como Irán (si bien, por seguir con este ejemplo, el régimen de los «ayatollahs» se repliega hacia sus fronteras y apuesta por la vía desarrollista-autoritaria). En fin, hay países islámicos anegados por la guerra civil (Argelia) y otros que buscan un frágil equilibrio entre sus simpatías pro occidentales y su fidelidad al sustrato religioso (Jordania, Egipto). Sin olvidar que «Islam» no es lo mismo que "países árabes» (puesto que la población musulmana más numerosa habita en países asiáticos como Pakistán, Malasia e Indonesia).

En segundo lugar, el teatro mundial de operaciones pone de manifiesto el nuevo clima de acuerdo entre viejas potencias enemigas. ¿Quién hubiera imaginado hace no tantos años el entendimiento sin apenas fisuras entre rusos y norteamericanos? ¿O la disposición simultáneamente pro rusa y pro americana de China?

En fin, la creciente investigación en torno a $\mathrm{Al}$ Qaeda y sus redes permite identificar mejor el foco del conflicto, librándolo de adherencias mitómanas.

El problema, entonces, es explicar la aparición y virulencia del movimiento capitaneado por Bin Laden y, más concretamente, su salto del antiamericanismo ideológico al antiamericanismo violento a gran escala.

Desde las filas de los Estados Unidos, evidentemente, existen hechos sobre los que reflexionar: su cambiante y coyuntural política de alianzas, su titubeo en la búsqueda de paz en Oriente Medio y, más concretamente, en la cuestión palestino-israelí, su estilo hegemónico o de «liderazgo nato». Sin embargo, el antiamericanismo hunde sus raíces en fenómenos variados y de largo alcance. Lo han resumido muy bien Ian Buruma y Avishai Margalit en su excelente artículo "Occidentalismo», publicado por el New York Review of Books del 17 de enero de 2002. Afirman en concreto los autores:

«El occidentalismo, que tan amplio papel jugó en los ataques del 11 de septiembre, es un racimo de imágenes e ideas sobre Occidente que puebla las mentes de quienes odian a este último. Hay cuatro grandes rasgos que se dan cita en la mayoría de las versiones de tal occidentalismo, a saber: la Ciudad, el Burgués, la Razón y el Feminismo. Todos ellos incluyen una serie de atributos — arrogancia, debilidad, avaricia, depravación, decadencia-, invocados como caracteres típicamente occidentales o incluso típicamente norteamericanos. No obstante, conviene no 
confundir el odio hacia Occidente con el odio hacia los Estados Unidos. Hay quienes odian a los Estados Unidos porque éstos les ayudaron y hay quienes les odian porque no les ayudaron. Algunos se resienten por la forma en que los Estados Unidos apoyaron o hicieron permanecer en el poder a gobiernos odiosos. Otros se sienten humillados por la existencia misma de los Estados Unidos o por su política exterior. Desde la izquierda, la condena de los Estados Unidos se considera un último vestigio de izquierdismo, un componente de una determinada identidad política. Y lo mismo puede decirse del gaullismo cultural de derechas. Antiamericanismo y occidentalismo no coinciden exactamente, si bien el primero suministra un importante contenido político al segundo».

Aun a riesgo de fatigar al lector con las citas, creo que merece la pena reproducir también la conclusión a la que llegan los mencionados autores en su trabajo:

«No hay choque de civilizaciones. La mayoría de religiones, especialmente las monoteístas, tienen la capacidad de albergar el veneno antioccidental. Y todas las culturas pueden producir variantes del fascismo secular. El conflicto contemporáneo, así pues, no se da entre el Este y el Oeste, Angloamérica y el resto del mundo o la comunidad judeocristiana y el Islam. El culto a la muerte es un virus letal que ahora, por causa de una amplia gama de razones históricas y políticas, arrastra a las facciones más extremistas del Islam (...). No podemos, por tanto, responder al occidentalismo con una no menos odiosa caricatura antioriental u "orientalista". Si caemos en esa tentación, el virus también nos habrá infectado a nosotros».

Volvemos, entonces, a la pregunta contenida en un párrafo anterior: ¿por qué se consolida con tal grado de virulencia una organización como Al Qaeda? Hemos visto desfilar en líneas precedentes algunas de las posibles explicaciones, de signo ideológico, histórico, estructural o geoestratégico. Si hubiera que resumir, de entre toda esa vasta panoplia, probablemente nos quedarían dos componentes básicos para la respuesta: por un lado, los zigzagueantes desarrollos de un programa de modernización y globalización incapaz de remediar los desequilibrios económicos y la lacerante desigualdad de oportunidades; por otro lado, en el contexto musulmán, la frustración de unas generaciones jóvenes que, como ha analizado brillantemente el politólogo marroquí A. Lamchichi, buscan en el reenderezamiento de la política islámica y el apoyo a la causa palestina una alternativa efectiva y movilizadora a las ideologías nacionalistas que impulsaron a las generaciones maduras, protagonistas de los procesos de independencia y descolonización.

Y llegamos al núcleo duro del problema, esto es, la guerra abierta palestino-israelí. ¿Qué voy a afirmar que no esté dicho y redicho? El sentido común 
hace que cualquiera deplore el fracaso del plan de paz de Oslo (entre otras cosas, a causa del asesinato de Rabin). También el sentido común parece estar del lado de Edward Said cuando mantiene que, ya que israelitas y palestinos no pueden vivir juntos en el mismo Estado, debería crearse un Estado palestino con fronteras justas y seguras que coexistiera con el de Israel hasta que algún día ambos superaran su mutua incomprensión (y todo ello tras un arreglo definitivo del estatuto capitalino de la ciudad de Jerusalén y el fin de la ocupación de territorios). Nada más y nada menos. Si no fuera porque está en juego demasiada sangre y demasiada tragedia, recordaría explícitamente la conocida fábula de los ratones, el gato y el cascabel. No faltan, entretanto, voces firmes que se atreven a formular en alto opiniones para cuya puesta en marcha haría falta, desde luego, mucho coraje político. Por ejemplo, la de Tony Judt (curiosamente, en el mismo ejemplar del New York Review of Books ya citado). Afirma en concreto Judt:

«Recuerdo que en 1965 Golda Meier me llamó la atención por emplear la palabra "palestino" en una discusión pública. "No existe cosa parecida a un 'palestino'. No existe la nación palestina ni nunca existirá”, me advirtió. Que la futura primera ministra de Israel estuviera o no en lo cierto entonces no importa ya nada ahora. En estos momentos no está en lo cierto. Claro que existe una nación palestina, ayudada además en su creación por la actitud israelí. Esta nación se comporta de manera parecida en parte a la de otros pueblos de la historia reciente: así, De Valera y los nacionalistas irlandeses antes de 1922, los rebeldes MauMau de Kenya en los primeros años cincuenta, los judíos de Palestina antes de 1948. Y, como ellos, logrará antes o después sus propósitos, convirtiéndose esos terroristas a los que Sharon quiere eliminar bajo el manto de la venganza norteamericana - tan terroristas como lo fueron en su tiempo los mentores políticos de Sharon, Shamir y Begin- en los interlocutores políticos del mañana. Y pudiera ser que - como muchos israelitas y palestinos aceptan tácitamente y en el fondo desean- tal suerte de desenlace fuera impuesta a ambas partes por unos Estados Unidos afectados por la frustración».

El recorrido a galope que he efectuado por nuestro desconcertante presente pienso que no ha eludido los firmes retos que se alzan frente a las por mí profesadas esperanzas en el programa postilustrado. Pero tampoco pienso que las haya rebatido totalmente. Simplemente, las sitúa ante sus propias dificultades.

Esas esperanzas, si es que logran cumplirse, deberán abrirse camino en todos los frentes. Uno de ellos - y no el menos importante- es el de la renovación del discurso público democrático, político y parapolítico. Quisiera acabar esta contribución con una somera reflexión acerca de la necesidad de depurar al discurso público occidental del lastre de mesianismo político que todavía pudiera afectarle (de otra clase de discursos no democráticos, obviamente, no 
me ocuparé). Para ello utilizaré, como punto de partida y antirreferente, la consagrada terminología de Carl Schmitt.

\section{POR EL FIN DE LA «TEOLOGÍA POLÍTICA»}

En un muy reciente libro, The reckless mind. Intellectuals in politics, Mark Lilla, profesor de Pensamiento Social de la Universidad de Chicago, reflexiona, a través de una serie de agudos y ágiles retratos de muy conocidos intelectuales alemanes y franceses del siglo XX, sobre la enojosa relación entre los intelectuales y la política (o "el brillo de Siracusa», como denomina Lilla al atractivo que el poder político despierta en el siempre vanidoso intelectual, recordando la conocida experiencia de Platón como imposible preceptor del tirano de Sicilia).

Las figuras escogidas - tanto de izquierdas como de derechas- son: el «triángulo» formado por Heidegger, Arendt y Jaspers; Carl Schmitt; Walter Benjamin; Alexandre Kojève, Michel Foucault y Jacques Derrida. No voy a realizar aquí una elaborada recensión que no procede; sí que recordaré cómo el autor toma y retoma en su ensayo un fondo común que aletea en las variadísimas peripecias de tiempo y lugar de sus personajes. Me refiero a la manera en que cualquier intelectual tiende a pensar que las eventuales repercusiones políticas de su propia obra forman parte de un designio correcto que, en uno u otro momento, debería influir en las constelaciones ideológicas prevalecientes. De forma más o menos explícita, por decirlo con otras palabras, el intelectual se siente tentado a definir el curso de los acontecimientos, moldeando a la realidad más que interpretándola críticamente. En los casos extremos, esta tentación deviene crasa asesoría de gobiernos sobre cuya raíz moral puede llegar uno a no preguntarse. La tentación mesiánica, que define de suyo a los ideólogos revolucionarios o seudorrevolucionarios, estaría en condiciones de permear, quizá ocultamente, la teoría política de todos los colores.

El estereotipo de lo anterior es, para Lilla, Carl Schmitt. Y no exclusivamente por su conocida adhesión al nazismo, sino por el fondo de su concepción soberanista y crudamente conflictual de la política. En efecto, Schmitt identifica orden político con el ejercicio de la soberanía propia de las potencias históricas - y, naturalmente, Deutschland über alles-. Pero no se trata sólo de esto. Ocurre también que el precario equilibrio entre potencias soberanas debe entenderse como una prolongación secular de los viejos combates entre dioses y demonios, como una «teología política». Si Schmitt es deudor del Hobbes más agresivo y preimperialista (un Hobbes que no tiene nada que ver con el realista descubridor de la máxima homo homini lupus, que es el Hobbes al que yo he reivindicado antes), en idéntica medida lo es del más lúgubre y estéticamente atractivo William Blake.

Ésa es la clase de tentación sobre la que el autor generaliza, siquiera tentativamente, al final de su obra. Y ésa es la clase de tentación que nosotros debe- 
ríamos pensar si se da o no en las actuales concepciones en activo de la política democrática.

Si el liberalismo constituye, sin duda, una de las corrientes de fondo más caudalosas de esa tradición política democrática, debería ser probablemente por él por donde deberíamos empezar a la hora de reflexionar sobre tal hipotética tentación. Y para ello nos resulta de clara ayuda el libro de John Gray, Las dos caras del liberalismo.

Analiza en esta obra el teórico inglés la manera en la que el liberalismo, incluso en sus versiones menos instrumentales y más centradas en los pilares del pluralismo y la defensa civilizada de posturas contrapuestas como ideales o fines en sí mismos — así, el liberalismo de John Rawls_- es proclive a incurrir en un vago sentimiento redentorista que debería ir cediendo el turno — siempre según Gray - a otro tipo de defensa de lo liberal. De lo que se trataría ahora es de apostar por la conservación de un determinado modus vivendi que no trae consigo la verdad final, pero sí un razonable grado de articulación y entendimiento. No es cuestión, claro está, de caer en un relativismo cínico, sino de eliminar de las esperanzas de futuro todo sesgo o exceso prescriptivo. Gray concluye su libro precisamente con tal afirmación, que expresa como sigue:

«Sería vano negar que el modus vivendi es una concepción escéptica. Pero lo que no niega es la idea de que podemos apreciar la diferencia entre lo correcto y lo erróneo. Lo que niega es la creencia tradicional, heredada por la ortodoxia liberal contemporánea, de que los conflictos de valor no pueden tener más que una solución correcta. Abandonar esta idea no representa ninguna pérdida, puesto que supone que la diversidad de modos de vida y de regímenes es un signo de libertad humana, no un signo de error. La tolerancia liberal intentó atemperar las argumentaciones universales rivales sobre el bien y sobre el mal con un desacuerdo razonable, pero nunca abandonó la esperanza de alcanzar un consenso racional sobre el mejor modo de vida posible para la humanidad. El modus vivendi continúa la búsqueda liberal de la coexistencia pacífica, pero lo hace dejando atrás la creencia en que un modo de vida o un único tipo de régimen podrían resultar los mejores para todos».

Si dirigimos el ámbito de influencia de una opinión como la anterior al conjunto de la política democrática contemporánea y no sólo a una de sus familias ideológicas, probablemente el corolario se identificaría con la apuesta por un ethos o práctica que hiciera del viejo «ideal de la humanidad» no la culminación de un programa misionero, sino un crisol de energías abiertas.

Abandonemos, en cualquier caso, la retórica y entremos en la realidad. Recojamos, por ejemplo, de entre esta última, el actual clima de alianza internacional del que antes hablábamos. ¿Es que solamente puede dar como fruto tangible la guerra de Afganistán? ¿No podrían los socios de la alianza aprove- 
char la terrible ocasión que se les brinda para empezar a encarar con honradez, no exenta de realismo, el reto de la globalización (lo cual, por cierto, no es más que una forma resumida de referirse a un tronco ingente de problemas tales como la política demográfica y el desafío medioambiental)?

Ya sé que no se puede pecar de ingenuo y que en este mundo los problemas no se resuelven en tertulia. Pero si no se hace otra cosa que cavar fosos, es posible no ya que se agite triunfante el espantajo del «choque de civilizaciones», sino que peligre la noción misma de civilización. 


\section{CRÍTICA DE LIBROS}

